\title{
Early computed tomography for acute post-traumatic diffuse axonal injury: a systematic review
}

\author{
Giovana Figueira Rodrigues Vieira ${ }^{1}$ (D) José Fernando Guedes Correa ${ }^{1}$
}

Received: 6 January 2020 / Accepted: 17 February 2020 / Published online: 4 March 2020

(C) Springer-Verlag GmbH Germany, part of Springer Nature 2020

\begin{abstract}
Purpose Diffuse axonal injury (DAI) is the rupture of multiple axons due to acceleration and deceleration forces during a closed head injury. Most traumatic brain injuries (TBI) have some degree of DAI, especially severe TBI. Computed tomography (CT) remains the first imaging test performed in the acute phase of TBI, but has low sensitivity for detecting DAI, since DAI is a cellular lesion. The aim of this study is to search in the literature for CT signs, in the first $24 \mathrm{~h}$ after TBI, that may help to differentiate patients in groups with a better versus worst prognosis.

Methods We searched for primary scientific articles in the PubMed database, in English, indexed since January 1st, 2000.

Results Five articles were selected for review. In the DAI group, traffic accidents accounted $70 \%$ of the cases, $79 \%$ were male, and the mean age was 41 years. There was an association between DAI and intraventricular hemorrhage (IVH) and traumatic subarachnoid hemorrhage (tSAH); an association between the IVH grade and number of corpus callosum lesions; and an association between blood in the interpeduncular cisterns (IPC) and brainstem lesions.

Conclusion In closed TBI with no tSAH, severe DAI is unlikely. Similarly, in the absence of IVH, any DAI is unlikely. If there is IVH, patients generally are clinically worse; and the more ventricles affected, the worse the prognosis.
\end{abstract}

Keywords Diffuse axonal injury $\cdot$ Computed tomography $\cdot$ Traumatic brain injury $\cdot$ Post-traumatic coma

\section{Introduction}

Diffuse axonal injury (DAI) is a lesion in cerebral white matter that occurs during traumatic brain injuries (TBI), most commonly caused by mechanisms involving simultaneous linear and angular acceleration and deceleration of the head, generating rupture of neuronal axons [1-3]. It is defined as a diffuse injury to the axons in the cerebral hemispheres, the corpus callosum, the brainstem, and, sometimes, the cerebellum, as a result of a TBI. Concurrently, there is vascular injury at a capillary level, which can be seen in the early stages as isolat-

Giovana Figueira Rodrigues Vieira

giovana_frvieira@hotmail.com

José Fernando Guedes Correa

neuroguedes@yahoo.com.br

1 Department of Neurosurgery, Gaffrée e Guinle University Hospital, School of Medicine, Federal University of Rio de Janeiro State, 775 Mariz e Barros Street, Rio de Janeiro, RJ, Brazil ed or multiple hemorrhages at the junction of white and gray matter [3].

As observed by Gennarelli et al. [4], depending on its nature, a TBI can cause several degrees of lost consciousness, ranging from concussion without apparent sequelae (when the coma lasts under $15 \mathrm{~min}$ ) to prolonged coma with bilateral decerebration and incomplete neurological recovery. The duration of coma, outcomes, and post-traumatic dysfunction observed in the primates used in Gennarelli's study also were directly linked to the direction of head movement, with coma duration, degree of post-traumatic dysfunction, and extent of DAI increasing from sagittal to oblique to lateral acceleration [4].

Clinically, DAI is defined as a prolonged post-traumatic coma of at least $6 \mathrm{~h}$ after a TBI without demonstrable mass lesions. The clinical classification of DAI has three degrees: mild, moderate, and severe, as summarized in Table 1. In mild DAI, the coma lasts from 6 to $24 \mathrm{~h}$. In moderate DAI, the coma lasts for more than $24 \mathrm{~h}$, without abnormal postures. In severe DAI, the coma lasts for more than $24 \mathrm{~h}$ and there are signs of brainstem deficit. Many patients classified as severe DAI will either die or never recover useful function. 
Table 1 Clinical classification of DAI

\begin{tabular}{ll}
\hline Grade & Clinical findings \\
\hline Mild & Coma $<6-24 \mathrm{~h}$ \\
Moderate & Coma $>24 \mathrm{~h}$, without abnormal postures \\
Severe & Coma $>24 \mathrm{~h}$, with signs of brainstem deficit \\
\hline
\end{tabular}

Source: Adams et al. (1982)

Classical concussion was defined by Gennarelli et al. as a coma that lasts for less than $15 \mathrm{~min}$, starting during the moment of acceleration, and accompanied by the absence of ocular opening and ability to follow visual stimuli with the eyes, the absence of a corneal reflex, and mydriasis. The corneal areflexia lasts from $30 \mathrm{~s}$ to $5 \mathrm{~min}$ and coincides with the return of ocular opening and behavioral wakefulness. Patients go straight from the initial phase of coma to the recovery phase, and ultimately experience good neurological recovery $[4,5]$.

Histopathologically, DAI is divided into three degrees, of increasing severity, as seen in Table 2 . With grade 1 injuries, there is histological evidence of axonal lesions in the white matter of the cerebral hemispheres. With grade 2, there is also at least one focal lesion in the corpus callosum. With grade 3 , there is also a focal lesion in the dorsolateral quadrant or in the rostral quadrants of the brainstem. There is a close correlation between the degree of diffuse axonal injury and the severity of cranioencephalic trauma [3]. There may also be other macroscopic findings, like small amounts of blood in the subarachnoid space, and subdural or rarely frontal or temporal contusions, in addition to focal lesions in the corpus callosum or upper cerebellar peduncle in the most severe cases [4].

About $3 / 4$ of all patients with a TBI present with some degree of DAI. With severe TBI, DAI is found in almost all cases [6]. Most patients with mild to moderate DAI have some medium to long-term recovery. However, in patients with severe DAI, death is the most common outcome $[6,7]$. Among the group with non-fatal outcome, the prevalence of disability and dependence several months after the trauma is high, varying from $40-87.5 \%$ to $20-40 \%$, respectively, with severe DAI the main risk factor [7].

Table 2 Histopathological classification of DAI

Grade Histopathological findings

\begin{tabular}{l}
\hline Evidence of axonal injury in the white matter of the cerebral \\
hemispheres
\end{tabular}

Source: Gennarelli et al. (1982)
The clinical evaluation of DAI includes the Extended Glasgow Outcome Scale (GOSE), a global scale for assessing patients' functional outcomes, divided into eight categories: (1) dead; (2) vegetative state; (3) lower severe disability; (4) upper severe disability; (5) lower moderate disability; (6) upper moderate disability; (7) lower good recovery; (8) upper good recovery. The recommended time to apply the scale is 3 months after trauma, as well as at 6 months and 12 months. The scale is administered via a structured interview, postdischarge.

The highest prevalence of DAI is in young individuals, with a mean age of 28 years. The main cause of DAI is traffic accidents, followed by domestic accidents, sports accidents, assaults and accidents at work [8].

DAI is known to have cognitive, somatic and emotional sequelae, and to predispose individuals to specific psychiatric disorders and cerebral atrophy [9-11]. Approximately 50\% of patients present with moderate to severe deficits related to learning and the retention of new information, while attention and executive functions are slightly altered [9].

In the acute phase, the diagnosis of DAI is suggested by the combination of clinical symptoms and the absence of any apparent mass lesions on computed tomography (CT), or the presence of microhemorrhages at the junction of white and gray matter [8, 12]. Other neuroimaging methods - like diffusional magnetic resonance imaging (MRI) and probabilistic tractography, which evaluates the connectivity of neural networks - are used to follow patients after the acute phase [12].

Computed tomography (CT) is the examination of choice in the acute phase of TBI, as it is more accessible and faster than MRI and other imaging modalities. The diagnosis of DAI by CT is suggested by the presence of small non-expansive hemorrhagic lesions in the areas of connection between white and gray matter, by the presence of blood in the intraventricular space and, eventually, by generalized cerebral edema [13].

However, MRI detects up to three times more intraparenchymal lesions than CT. Approximately $75 \%$ of patients with a clinical picture suggestive of DAI and normal CT images at an early stage have intraparenchymal abnormalities on MRI [14]. However, as MRI is a time-consuming exam and cannot be done in patients with ferromagnetic devices; it is typically impossible for it to be done during the acute phase of TBI, during which patients are generally hemodynamically unstable and require monitoring devices [14].

Due to the high incidence of traffic accidents, and with DAI present in most severe TBI, this is a highly prevalent condition in Brazil, and leads to severe sequelae both for the patient and for society, as many patients become unable to work and require extended hospital and post-hospital care. Furthermore, because DAI is a complicated diagnosis in its acute phase, it would be helpful to identify CT patterns that allow clinicians to predict patients' prognosis and guide therapy. 


\section{Methods}

This systematic review of published studies was undertaken using the PubMed database. The search was performed on January 31st, 2019, at which time only articles written in English were examined. The time period for eligible studies was from January 1st, 2000, onward, and the search strategy employed the following terms: "diffuse axonal injury" AND "computed tomography."

We selected the following study inclusion criteria: (1) patients had to have had a CT exam within $24 \mathrm{~h}$ of their TBI; and (2) the studies had to show CT results for DAI. We excluded case reports. Data were extracted from the selected papers pertaining to the following: (1) article publication (author and year); (2) study design; (3) study population (sample size, gender distribution, age, type of accident and GCS), (4) CT findings; and (5) DAI classification (Table 3).

\section{Results}

Our primary literature search on PubMed identified 97 articles. After applying the date of publication and language filters, 76 articles remained. After applying the inclusion and exclusion criteria, 13 articles remained. Ultimately, with fulltext analysis, five papers were selected for review (Fig. 1).

The total sample was of 1245 patients with TBI, of which $414(33.25 \%)$ had DAI.

Samples were divided into two large groups: DAI (+), corresponding to patients diagnosed with DAI, and DAI (-), patients no diagnosed with DAI. DAI grades 2 and 3 were considered severe DAI, consistent with Gennarelli et al.'s classification.

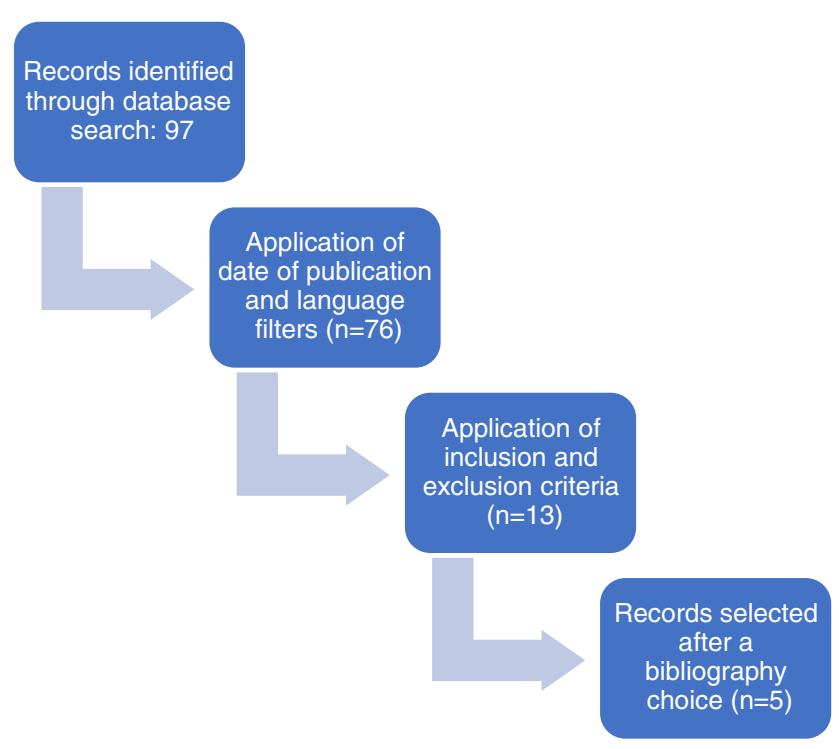

Fig. 1 PRISMA flowchart depicting the literature search. Source: Flowchart created by author
Note that, in Tables 3 and 4, subjects in the article by Henninger et al. [15]. are divided into two subgroups: positive hemorrhagic DAI and negative hemorrhagic DAI.

In all five articles, data were collected retrospectively. In all five papers, patients underwent CT within the first $24 \mathrm{~h}$ after trauma and later underwent MRI. The duration of time from injury to MRI varied between studies, from $24 \mathrm{~h}$ after trauma to several weeks. Comparisons between CT and MRI findings are summarized in Table 4.

In all the studies, there was analysis of the demographic factors of age, sex and mechanism of injury, and all had findings that were concordant with those already reported in the literature: that DAI is more common in younger patients, in males, and caused by high-energy mechanisms like traffic accidents. On the other hand, it is more severe in older patients.

All the studies analyzed the outcomes using the GOSE score, with the time of GOSE score application varying between the studies. All the studies generally determined that patients with severe DAI (stages II or III) exhibited a significantly lower GOSE score.

Only the Henninger et al. study exclusively selected patients with mild TBI (GCS score $\geq 12$ ), which might explain how some of its findings were discordant with those of the other studies. The Beretta et al. study [16] only evaluated patients with severe TBI (GCS <9). Mata-Mbemba et al., in their two studies $[17,18]$, evaluated patients with closed TBI without subdividing the sample by condition severity. Likewise, Matsukawa et al. assessed patients with isolated TBI, without trauma to other organs or systems that warranted immediate intervention.

Only the Beretta study excluded patients with posttraumatic intracranial lesions that do not enter the spectrum of DAI, such as hematomas and brain contusion. The other studies did not exclude these patients, which may have biased results.

In all studies, patients were grouped according to the Adams classification: (0) negative DAI; (1) lesions suggestive of DAI in the white matter or cerebellum; (2) DAI in the corpus callosum; (3) DAI in the brainstem. Henninger further subdivided patients into those with hemorrhagic DAI (hDAI), which was defined as the presence of one or more punctate hemorrhages on CT, and non-hemorrhagic DAI. Henninger divided his patients into three groups: predominant hDAI, in which there was no coexistence with mass lesions, associated hDAI, and negative hDAI.

The results of the articles were compared. There was a significant statistical difference between the DAI (+) group and the DAI (-) group regarding the mechanism of trauma, with traffic accidents much more common in the DAI $(+)$ $(70 \%)$ than in the DAI (-) $(40 \%)$ patient group, likely due to the mechanism of trauma, which requires high energy and rotational acceleration and deceleration of the head to cause 
Table 3 Demographic and clinical characteristics of patients

\begin{tabular}{|c|c|c|c|c|c|}
\hline Author and Year & Number of patients & Mean age (years) & Sex & Type of accident & GCS \\
\hline Mata-Mbemba et al., 2018 (DAI (-)) & 193 & $43.8 \pm 23.9$ & $\begin{array}{l}\text { Male: } 73.6 \% \\
\text { Female: } 26.4 \%\end{array}$ & $\begin{array}{l}\text { Traffic: } 54.9 \% \\
\text { Fall: } 36.8 \% \\
\text { Other: } 8.3 \%\end{array}$ & Mean: $13.3 \pm 2.6$ \\
\hline Mata-Mbemba et al., 2018 (DAI (+)) & 77 & $41.2 \pm 21.9$ & $\begin{array}{l}\text { Male: } 72.7 \% \\
\text { Female: } 27.3 \%\end{array}$ & $\begin{array}{l}\text { Traffic: } 70.1 \% \\
\text { Fall: } 28.6 \% \\
\text { Other: } 1.3 \%\end{array}$ & Mean: $10.7 \pm 3.8$ \\
\hline Henninger et al., 2018 (hDAI (-)) & 291 & $56(36 ; 72)$ & $\begin{array}{l}\text { Male: } 71 \% \\
\text { Female: } 29 \%\end{array}$ & $\begin{array}{l}\text { High velocity: } 32 \% \\
\text { Fall: } 54 \% \\
\text { Other: } 14 \%\end{array}$ & Not stated \\
\hline Henninger et al., 2018 (hDAI (+)) & 70 & 32 & $\begin{array}{l}\text { Male: } 77 \% \\
\text { Female: } 23 \%\end{array}$ & $\begin{array}{l}\text { High velocity: } 79 \% \\
\text { Fall: } 17 \% \\
\text { Other: } 4 \%\end{array}$ & Not stated \\
\hline Mata-Mbemba et al., 2014 (DAI (-)) & 92 & $41.9 \pm 3.9$ & $\begin{array}{l}\text { Male: } 66 \% \\
\text { Female: } 34 \%\end{array}$ & $\begin{array}{l}\text { Traffic: } 62 \% \\
\text { Fall: } 35.9 \% \\
\text { Other: } 2.1 \%\end{array}$ & $\begin{array}{l}13-15: 73.9 \% \\
9-12: 15.2 \% \\
8 \text { or less: } 7.6 \%\end{array}$ \\
\hline Mata-Mbemba et al., 2014 (DAI (+)) & 48 & 41.3 & $\begin{array}{l}\text { Male: } 85.4 \% \\
\text { Female: } 14.6 \%\end{array}$ & $\begin{array}{l}\text { Traffic: } 77.1 \% \\
\text { Fall: } 20.8 \% \\
\text { Other: } 2.1 \%\end{array}$ & $\begin{array}{l}13-15: 43.7 \% \\
9-12: 27.1 \% \\
8 \text { or less: } 18.7 \%\end{array}$ \\
\hline Matsukawa et al., 2012 (DAI (-)) & 318 & $52.1 \pm 21$ & $\begin{array}{l}\text { Male: } 79.6 \% \\
\text { Female: } 20.4 \%\end{array}$ & $\begin{array}{l}\text { Traffic: } 30.5 \% \\
\text { Fall: } 65.7 \% \\
\text { Other: } 3.8 \%\end{array}$ & $\begin{array}{l}\text { 13-15: } 84.6 \% \\
9-12: 7.2 \% \\
8 \text { or less: } 8.2 \% \\
\text { Median: } 14\end{array}$ \\
\hline Matsukawa et al., $2012(\mathrm{DAI}(+))$ & 53 & $51.2 \pm 21.6$ & $\begin{array}{l}\text { Male: } 83 \% \\
\text { Female: } 17 \%\end{array}$ & $\begin{array}{l}\text { Traffic: } 52.8 \% \\
\text { Fall: } 47.2 \% \\
\text { Other: } 0 \%\end{array}$ & $\begin{array}{l}13-15: 52.8 \% \\
9-12: 22.6 \% \\
8 \text { or less: } 24.5 \% \\
\text { Median: } 13\end{array}$ \\
\hline Beretta et al., 2010 & 102 & $30.5 \pm 15.5$ & $\begin{array}{l}\text { Male: } 79 \% \\
\text { Female: } 21 \%\end{array}$ & Not stated & Median of 6 \\
\hline
\end{tabular}

Source: Table created by author

axonal rupture. Meanwhile, in the DAI (-) group, a higher proportion of patients had suffered falls (52\%), which had a higher correlation with traumatic mass lesions, like hematomas and cerebral contusions (Fig. 2).

There was also a statistically significant difference in age between the groups: DAI (+) patients averaged 41 years, whereas DAI (-) patients averaged 51 years old (Fig. 3). This also relates to the mechanism of trauma, since older patients had a higher prevalence of TBI due to falls, possibly caused by postural instability.

Regarding patient gender, the two patient groups were statistically similar, with males markedly outnumbering females in both groups: DAI(+) 79\%; DAI (-) 74\% (Fig. 4).

Mata-Mbemba et al. (2018), assessed the relationship between both traumatic subarachnoid hemorrhage (tSAH) and intraventricular hemorrhage (IVH), jointly and alone, on the initial CT, and MRI findings. For tSAH, five locations were evaluated: cerebral convexities, Sylvian fissures, Sylvian vallecula, the interhemispheric fissure, and peri-mesencephalic cisterns. A significant association between $\mathrm{tSAH}$ on initial CT and DAI on MRI was demonstrated, with tSAH identified on $49.4 \%$ of CTs in patients whose MRI demonstrated DAI.
Of the patients with severe DAI (grades II and III), 78.4\% had tSAH, and $60.8 \%$ had midline $\mathrm{tSAH}$.

The composite IVH/tSAH item was independently associated with DAI. When separated, IVH and tSAH also were associated with DAI. Only interhemispheric and perimesencephalic tSAH were independently associated with both general DAI and severe DAI.

The presence of midline tSAH on the initial CT had a sensitivity of $60.8 \%$, a specificity of $81.7 \%$, a positive predictive value of $43.7 \%$, and a negative predictive value of $89.9 \%$ for predicting severe DAI. In other words, when midline tSAH is not evident on CT, most likely the mechanism of TBI was not by shear forces, and DAI, if present, is likely not severe.

In their study, Henninger et al. found that, in their hemorrhagic DAI (hDAI) group, most of the patients were young, with more severe lesions and a higher propensity for hypotension. Overall, $70 \%$ had grade I, $3 \%$ grade II and $27 \%$ grade III DAI. In addition, hDAI had a higher frequency of systemic complications, like pneumonia, severe acute respiratory syndrome, sepsis and fever. Likewise, cerebral edema with the need for osmotherapy was more frequent in patients with 
Table 4 Relationship between CT findings and DAI classification

\begin{tabular}{|c|c|c|c|c|}
\hline $\begin{array}{l}\text { Author and } \\
\text { year }\end{array}$ & Sample & CT findings & $\begin{array}{l}\text { DAI } \\
\text { classification }\end{array}$ & Conclusion \\
\hline $\begin{array}{l}\text { Mata-Mbemba } \\
\text { et al., } 2018\end{array}$ & 270 & $\begin{array}{l}\text { Midline subarachnoid hemorrhage } \\
\text { (interhemispheric or } \\
\text { peri-mesencephalic) }\end{array}$ & II and III & $\begin{array}{l}\text { tSAH could implicate the same shearing mechanism that underlies } \\
\text { severe DAI, for which midline tSAH on initial CT is a probable } \\
\text { surrogate. } \\
\text { The absence of tSAH excludes severe DAI. } \\
\text { Midline tSAH is independently associated with poor early and } \\
\text { long-term outcome. }\end{array}$ \\
\hline $\begin{array}{l}\text { Henninger } \\
\text { et al., } 2018\end{array}$ & 361 & Hemorrhagic DAI & I & $\begin{array}{l}\text { hDAI is not an independent predictor of unfavorable short or long term } \\
\text { outcomes and should not be used for acute prognostication in } \\
\text { mild-severe TBI patients. }\end{array}$ \\
\hline $\begin{array}{l}\text { Mata-Mbemba } \\
\text { et al., } 2014\end{array}$ & 140 & Intraventricular hemorrhage (IVH) & II and III & $\begin{array}{l}\text { Higher IVH scores (number of ventricles in which IVH was seen) are } \\
\text { linked to higher DAI scores. } \\
\text { After TBI, the presence of IVH on initial CT should be considered a } \\
\text { marker of severe DAI. }\end{array}$ \\
\hline $\begin{array}{l}\text { Matsukawa } \\
\text { et al., } 2012\end{array}$ & 371 & IVH & II & $\begin{array}{l}\text { IVH is associated with corpus callosum injury. } \\
\text { The severity of IVH (number of ventricles in which IVH was seen) is } \\
\text { correlated with the number of lesions in the corpus callosum }\end{array}$ \\
\hline $\begin{array}{l}\text { Beretta et al., } \\
2010\end{array}$ & 102 & $\begin{array}{l}\text { Blood in the interpeduncular cistern } \\
\text { (IPC) }\end{array}$ & III & $\begin{array}{l}\text { Blood in the IPC indicates DAI in the brainstem, but is not correlated } \\
\text { with grade I or grade II DAI. } \\
\text { IPC blood exhibited an incremental trend from patients in grade II to } \\
\text { those in grade III on the modified Firshing scale. }\end{array}$ \\
\hline Total & 1245 & & & \\
\hline
\end{tabular}

Source: Table created by author

hDAI. However, hDAI had a lower risk of death at 1 year and better functional prognosis than patients without hDAI.

Mata-Mbemba et al. (2014) evaluated the relationship between the presence of both IVH and tSAH on the initial CT, and DAI on the subsequent MRI. Together, IVH and SAH were significantly associated with DAI in MRI; but, when separated, only IVH was a predictor of DAI. The IVH score (using the same classification as in the other 2018 study) and DAI stage were directly correlated, with the IVH score in patients with degree II or III DAI significantly higher than in patients without DAI. Thus, IVH on the initial CT exhibited high specificity and a high negative-predictive value for the presence of DAI, of $88 \%$ and $71.7 \%$, respectively. This means that the absence of IVH on the initial CT means that there is probably no DAI, and especially no severe DAI (group II or III).

In their study, Matsukawa et al. [19]. evaluated the relationship between IVH at baseline and grade II DAI (corpus callosum lesion) on MRI 2 weeks post TBI. The number of ventricles in which blood was present predicted IVH severity. The proportion of patients with a severe TBI (GCS <9), abnormal pupils, and a traffic accident as the mechanism of injury were significantly higher in patients with a corpus callosum lesion (CCI). IVH was significantly associated with CCI. The investigators also found that older age, male gender, low GCS, IVH on CT, and CCI on MRI all were associated

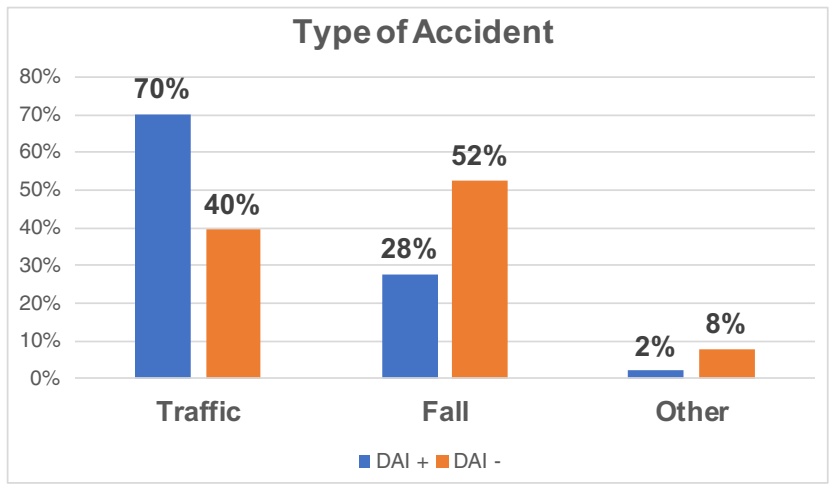

Fig. 2 Type of accident. Source: Figure created by author

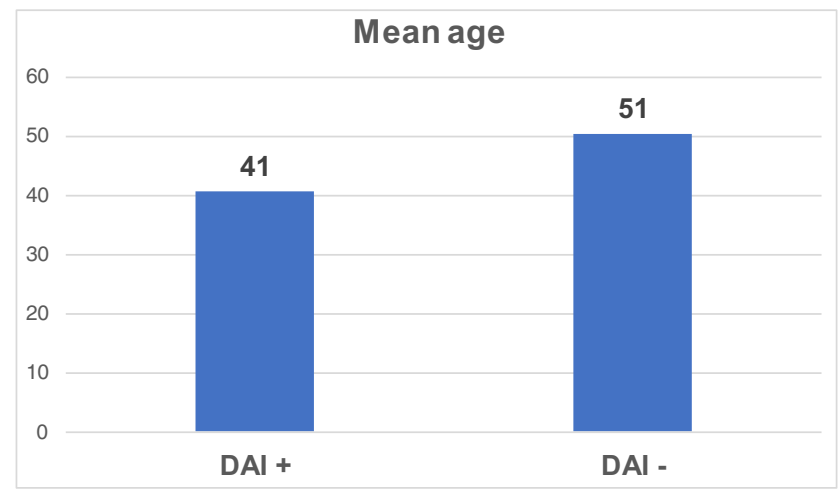

Fig. 3 Mean age. Source: Figure created by author 


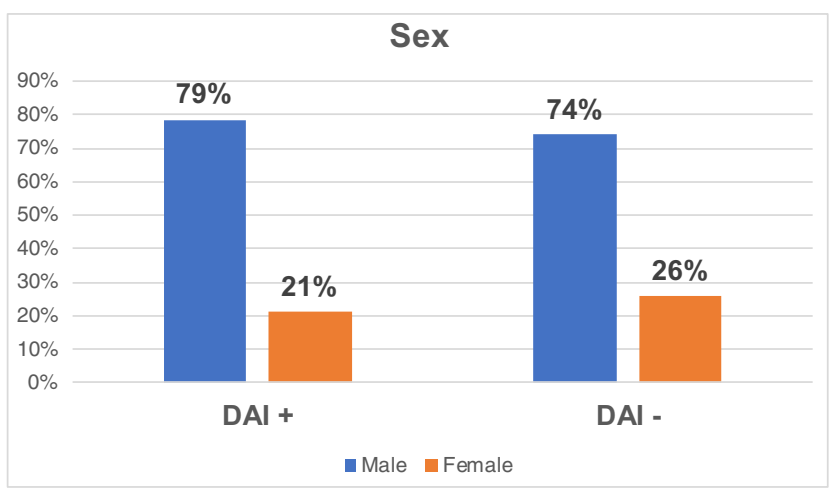

Fig. 4 Sex. Source: Figure created by author

with the future presence of disability (GOSE scale $\leq 6$ ). In addition, a direct correlation was identified between IVH grade and the number of CCI lesions.

Beretta et al. analyzed the relationship between blood in the interpeduncular cisterns (IPC) on CT and grade III DAI (brainstem lesion) on MRI. The severity of the brain stem lesion (BSL) was defined according to the modified Firshing classification: (I) supratentorial lesions or no lesions; (II) unilateral lesions in the brainstem at any level; (III) bilateral lesions in the brainstem at any level. Overall, $85.3 \%$ of patients had CCI on MRI, and $75.5 \%$ had a BSL. Patients with blood in the IPC averaged significantly lower GCS scores than those without blood in the IPC. Patients with evidence of BSL on MRI had a significantly higher incidence of blood in their IPC on CT. The finding of blood in the IPC did not differ significantly in patients with Firshing degrees II or III DAI, though it trended towards being higher in grade III.

\section{Discussion}

Worldwide, trauma causes $10 \%$ of all deaths, and trauma is the leading cause of permanent disability. Most traumatic events occur in individuals between 5 and 44 years old [20]. According to Datasus data from 2016, in Brazil, deaths due to external causes account for approximately $12 \%$ of all deaths. The age groups with the highest mortality due to external causes are those 15 to 59 years old. Males account for $82.2 \%$ of these externally caused deaths [21].

In Brazil, it is estimated that more than one million people live with neurological sequelae due to a TBI. Males are most affected, accounting for $81.5 \%$ of the mortalities caused by TBI. The most prevalent age group is up to 40 years. The main causes are traffic accidents, primarily involving motorcycles. And the mortality rate of TBI in Brazil is 12\% [21].

In our study, according to the criteria used, the incidence of DAI across all TBI patients was roughly $33 \%$. According to Adams et al., the incidence of DAI in closed TBI is $29 \%$, and that is likely to be an underestimate, since DAI may be camouflaged by other types of brain injury, like severe contusions, brain hematomas, brain injury secondary to intracranial hypertension, brain herniation leading to hemorrhage and infarction of the brainstem, and severe hypoxic injury [3]. In moderate to severe TBI, the prevalence of DAI is approximately $72 \%[6]$.

In a study by Vieira et al., $89.7 \%$ of patients with DAI were male, and $43.6 \%$ between 18 and 28 years of age, with a mean age of 32 years. The main cause of DAI in this study was traffic accidents, with motorcyclists accounting for $43.6 \%$ of these cases. Individuals in coma (GCS $\leq 8)$ constituted $75.7 \%$ of the patients. In this study, no patients were classified as having mild TBI, while $19.2 \%$ had moderate and $80.8 \%$ severe TBI. Out of the total, $53.8 \%$ underwent surgery, and $19.2 \%$ required repeat surgeries. Mortality after 6 months was $30.8 \%$. Among survivors, $88.2 \%$ achieved recovery consistent with independent life 6 months post DAI [7]. In the study by Adams et al., the incidence of traffic accidents in patients with DAI was much higher than that in patients without DAI, and the incidence of DAI was much lower in patients whose TBI resulted from a fall [21].

In this study, we found results compatible with the literature: the mean age of patients with DAI was 41 years, $79 \%$ were male, and $70 \%$ of DAI was caused by a traffic accident. Unfortunately, GCS was not comparable between studies, as some studies did not employ this evaluation parameter.

According to our findings, in a patient with a closed TBI and an early CT showing no tSAH, there is probably no severe DAI; similarly, in the absence of IVH, there is also probably no severe DAI. If there is IVH, it is possible that the patient is more severe and has a reserved prognosis, since there is, at least, CCI. In addition, the greater the number of ventricles affected, the more serious the clinical picture is. The presence of blood in the IPC gives a possible diagnosis of severe DAI, either grade II or III.

The corpus callosum and brainstem are midline structures intrinsically related to the ventricular system of the encephalon. When the neurons of those areas suffer axonal shredding, the same shearing strain causes rupture of the midline superficial vessels. This mechanism produces IVH and a midline subarachnoid hemorrhage (interhemispheric and peri-mesencephalic). Furthermore, the severity of the IVH is related to the severity of the DAI, because the greater the forces of the accident, the greater the shearing forces, both for axons and small vessels.

Moreover, the simple presence of petechial lesions on CT is not indicative of worse functional outcome $(\mathrm{GCS}<4)$ in the long term, but represents a greater chance of complications in the short and medium term, such as pneumonia, SARS, sepsis, cerebral edema with the need of osmotherapy, and, consequently, the need for constant monitoring.

Patients with DAI require intensive clinical care because of the condition in which they arrive in the emergency department. A reduced level of consciousness, with GCS lower with than without DAI, plus the need for orotracheal intubation for airway protection, tachypnea, hypoxia, cardiorespiratory arrest and 
changes in glycemia are components of the clinical picture. Survivors of the injury often require a prolonged hospital stay, the use of sedatives and other drugs, and neurosurgical approaches, and generally experience worse outcomes than patients with TBI but without DAI. In patients with severe DAI, death is the most common outcome, with the presence, at admission, of hypotension, hypoxia, hyperglycemia, and pupillary changes also predictive of increased mortality $[6,7]$.

The current study has both strengths and weaknesses. Its main strengths are the large sample of patients and availability of demographic and baseline CT data. One limitation that warrants comment is that the studies used in our review failed to exclude the presence of other post-traumatic brain lesions, which could bias outcomes. Furthermore, the interval between the GCS and GOSE assessments and initial MRI varied between the studies.

The implications of our study extend not just to the neurosurgical community, but to all physicians working with trauma patients. In the case of a patient with a closed TBI, obtaining a $\mathrm{CT}$ within the first $24 \mathrm{~h}$ can aid in both guiding therapy and predicting prognosis, in both the short and long term. Also, patients with DAI are more likely to have other complications, and patients with severe DAI should be kept under continuous monitoring.

The available literature does not give an answer about the relationship between increased intracranial pressure and DAI, a relationship which clearly warrants further research, since it would have direct implications for patient management. Future research also must assess DAI patients in whom the presence of other post-traumatic brain lesions has been excluded, as well as new treatment modalities for severe DAI.

\section{Conclusions}

Three main conclusions can be drawn from our systemic review of the literature: (1) that there is scarce literature on a subject as prevalent as DAI; (2) that patients with a closed TBI who exhibit IVH and/or blood in the IPC on a CT performed within the first $24 \mathrm{~h}$ post trauma, have a worse prognosis, and the greater the number of affected ventricles, the more serious the clinical picture is; and (3) that, conversely, among patients whose early CT does not demonstrate tSAH or IVH, there is probably no severe DAI and, therefore, a better prognosis.

Funding information No funding was received for this research. All authors certify that they have no affiliations with or involvement in any organization or entity with any financial (such as honoraria; educational grants; participation in speakers' bureaus; memberships, employment, consultancies, stock ownership, or other equity interest; and expert testimony or patent-licensing arrangements) or non-financial interests (such as personal or professional relationships, affiliations, knowledge or beliefs) pertaining to the subject matter or materials discussed in this manuscript.

\section{Compliance with ethical standards}

Conflict of interest The authors declare that they have no conflict of interest.

Ethical approval All procedures performed in the studies involving human participants were in accordance with the ethical standards of the institutional and/or national research committee and with the 1964 Helsinki declaration and its later amendments or comparable ethical standards.

Informed consent For this type of study informed consent is not required.

\section{References}

1. Adams JH, Graham DI, Murray LS, Scott G (1982) Diffuse axonal injury due to nonmissile head injury in humans: An analysis of 45 cases. Ann Neurol 12(6):557-563

2. Li XY, Li J, Feng DF, Gu L (2010) Diffuse axonal injury induced by simultaneous moderate linear and angular head accelerations in rats. Neuroscience 169(1):357-369

3. Adams JH, Doyle D, Ford I, Gennarelli TA, Graham DI, McLellan DR (1989) Diffuse axonal injury in head injury: definition, diagnosis and grading. Histopathology. 15(1):49-59

4. Gennarelli TA, Thibault LE, Adams JH, Graham DI, Thompson CJ, Marcincin RP (1982) Diffuse axonal injury and traumatic coma in the primate. Ann Neurol 12(6):564-574

5. Gennarelli TA (1993) Cerebral concussion and diffuse brain injuries. In: Cooper PR (ed) Head Injury, 3rd edn. Williams \& Wilkins, Baltimore, pp 137-158

6. Skandsen T, Kvistad KA, Solheim O, Strand IH, Folvik M, Vik A (2009) Prevalence and impact of diffuse axonal injury in patients with moderate and severe head injury: a cohort study of early magnetic resonance imaging findings and 1-year outcome. J Neuros 113(3):556-563

7. Vieira R d CA, Paiva WS, de Oliveira DV, Teixeira MJ, de Andrade AF, de Sousa RMC (2016) Diffuse Axonal Injury: Epidemiology, Outcome and Associated Risk Factors. Front Neurol

8. Chelly H, Chaari A, Daoud E, Dammak H, Medhioub F, Mnif J et al (2011) Diffuse axonal injury in patients with head injuries: an epidemiologic and prognosis study of 124 cases. J C Trauma 71(4): 838-846

9. Scheid R, Walther K, Guthke T, Preul C, von Cramon DY (2006) Cognitive Sequelae of Diffuse Axonal Injury. Arch Neurol 63(3): 418-424

10. Ding K, de la Plata CM, Wang JY, Mumphrey M, Moore C, Harper C et al (2008) Cerebral atrophy after traumatic white matter injury: correlation with acute neuroimaging and outcome. J Neurotrauma 25(12):1433-1440

11. Hellstrøm T, Westlye LT, Kaufmann T, Trung Doan N, Søberg HL, Sigurdardottir S, et al. White matter microstructure is associated with functional, cognitive and emotional symptoms 12 months after mild traumatic brain injury. Sci Rep. 2017 [cited November 5, 2017];7. Downloaded from: https://www.ncbi.nlm.nih.gov/pmc/ articles/PMC5653776/

12. Mitra J, Shen K, Ghose S, Bourgeat P, Fripp J, Salvado O et al (2016) Statistical machine learning to identify traumatic brain injury (TBI) from structural disconnections of white matter networks. NeuroImage 129(Supplement C):247-259

13. Levi L, Guilburd JN, Lemberger A, Soustiel JF, Feinsod M (1990) Diffuse Axonal Injury: Analysis of 100 Patients with Radiological Signs. Neurosurgery 27(3):429-432 
14. Buttram SDW, Garcia-Filion P, Miller J, Youssfi M, Brown SD, Dalton HJ et al (2015) Computed Tomography Vs Magnetic Resonance Imaging for Identifying Acute Lesions in Pediatric Traumatic Brain Injury. Hosp Pediatr 5(2):79-84

15. Henninger N, Compton RA, Khan MW, Carandang R, Hall W, Muehlschlegel S (2018) "Don’t lose hope early": hemorrhagic diffuse axonal injury on head computed tomography is not associated with poor outcome in moderate to severe traumatic brain injury patients. J Trauma Acute Care 84(3):473-482

16. Beretta L, Anzalone N, Dell'Acqua A, Calvi MR, Gemma M (2010) Post-traumatic Interpeduncular cistern hemorrhage as a marker for brainstem lesions. J Neurotrauma 27(3):509-514

17. Mata-Mbemba D, Mugikura S, Nakagawa A, Murata T, Ishii K, Kushimoto S et al (2018) Traumatic midline subarachnoid hemorrhage on initial computed tomography as a marker of severe diffuse axonal injury. JNS. 129(5):1317-1324

18. Mata-Mbemba D, Mugikura S, Nakagawa A, Murata T, Kato Y, Tatewaki Y, Li L, Takase K, Ishii K, Kushimoto S, Tominaga T, Takahashi S (2015) Intraventricular hemorrhage on initial computed tomography as marker of diffuse axonal injury after traumatic brain injury. J Neurotrauma 32(5):359-365

19. Matsukawa H, Shinoda M, Fujii M, Takahashi O, Murakata A, Yamamoto D et al (2012) Intraventricular hemorrhage on computed tomography and corpus callosum injury on magnetic resonance imaging in patients with isolated blunt traumatic brain injury. JNS. 117(2):334-339

20. Centers for Disease Control and Prevention (CDC), National Center for Injury Prevention and Control. Report to Congress on mild traumatic brain injury in the United States: steps to prevent a serious public health problem. Atlanta (GA): Centers for Disease Control and Prevention; 2003

21. Department of Informatics of SUS (DATASUS). Informações de saúde, Epidemiológicas e Morbidade: banco de dados. Available in: http://datasus.saude.gov.br/informacoes-de-saude/tabnet/ epidemiologicas-e-morbidade

Publisher's note Springer Nature remains neutral with regard to jurisdictional claims in published maps and institutional affiliations. 